Beatrix Busse*

\title{
Practices of discursive urban place-making in Brooklyn, New York: (hidden) digital and embodied discourse
}

\author{
https://doi.org/10.1515/text-2021-0003
}

Received January 8, 2021; accepted July 26, 2021; published online August 13, 2021

\begin{abstract}
This paper investigates practices of urban discursive place-making in selected neighborhoods of Brooklyn, New York. I investigate the forms and functions of hitherto neglected multimodal data - semiotic landscapes written on the body, (hidden) Wi-Fi Service Set Identifiers, that is, SSIDs or Wi-Fi names, and \#Brooklyn Tweets - and how I have compiled these into a corpus. The corpus currently consists of multivariate data including - among others - ca. 1.3 million words of semi-structured interviews with Brooklynites, ca. 8,000 photographs of the semiotic landscapes in Brooklyn, New York, and ca. 47,000 Wi-Fi SSIDs. The aim of this paper is to show which semiotic forms and constructions of both Wi-Fi SSIDs and \#Brooklyn Tweets take on foregrounded practices of socalled discursive urban-place-making and how these interact in the various neighborhoods of Brooklyn and in the virtual spheres related to them. I will show how these practices carry the potential for (re-)indexing specific social values of an urban neighborhood or even the borough itself and how Brooklynites and others comment on the respective neighborhoods. They position themselves in the social, cultural, political, and economic spheres of urbanity. The mixedmethods approach draws on corpus linguistic, sociolinguistic, and stylistic methodology.
\end{abstract}

Keywords: Brooklyn neighborhoods; corpus linguistics; digital discourse; discursiveplace-making; urbanity

\section{Introduction}

Part of a 2018-Zun-Lee-exhibition called "Father Figure - Exploring Alternate Notions of Black Fatherhood" at the Bronx Documentary Centre, the 2012-photograph

\footnotetext{
*Corresponding author: Beatrix Busse, Department of English, University of Cologne, AlbertusMagnus-Platz, 50931 Cologne, Germany, E-mail: beatrix.busse@uni-koeln.de. https://orcid.org/ 0000-0003-4696-6727
}

Ә Open Access. ๑ 2021 Beatrix Busse, published by De Gruyter. (c) BY the Creative Commons Attribution 4.0 International License. 
in Figure 1 (Lee 2012) shows the naked and tattooed back of Jerell Willis while carrying his son Fidel walking across the Brooklyn Bridge. ${ }^{1}$ The photograph, which I discovered online through a report about this exhibition, and which the artist Zun Lee allowed me to use for free for my academic research, is one of Zun Lee's attempts to photograph black fathers and families from different walks of life and in different US cities.

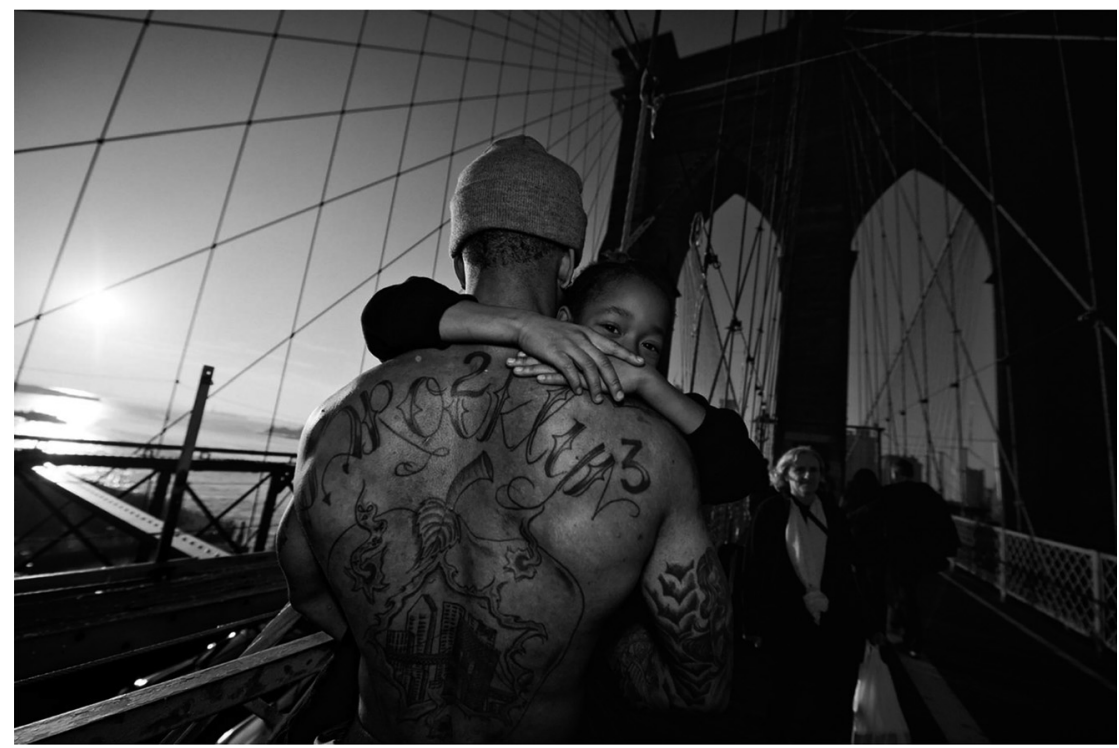

Figure 1: Jerell Willis carrying Fidel over the Brooklyn bridge in November 2012, @ Zun Lee.

For me, this photograph depicts an embodied, multimodal, and artistic variation of what I would like to call "discursive urban place-making" - that is, a process in which human agents use various semiotic means to attribute value and meaning to a spatial configuration. Brooklyn is multidimensionally branded as a place - through what is depicted in the photograph and through the fact that Zun Lee, as a photographer, decided to include this photograph in his exhibition.

1 I am honoured to contribute to this special issue in memory of Geoffrey Leech - an outstanding linguist and human being. Geoffrey Leech taught me how to be a real stylistician and corpus linguist, and he influenced my career at crucial moments. With humility and pride I pay my tribute and gratitude to Geoffrey Leech. Needless to say I would also like to thank the editors for including me in this wonderful project and for all the effort they have made in realizing this special issue. I would also like to thank the anonymous reviewers for their valuable advice. 
Initially, the value of Brooklyn is created by means of the generic reference to the name Brooklyn (see Busse 2019) and by the re-design of both the bridge on his back - with the famous waterfront view either from or to Manhattan - and the Big Apple symbolizing the city of New York. He makes a place with his Brooklyn tattoo on his naked back, which he intends to display on purpose and by walking over the famous bridge. His discursive act of place-making is artistically unique, as well as permanent and mobile in addition to being linguistically patterned, as we shall see below. Through the fact that this photograph became publicly displayed in Zun Lee's exhibition, Jerell Willis is granted the rare voice of a person of color.

This paper focuses on data of the embodied and the (hidden) digital urban sphere - semiotic landscape data on the body, Wi-Fi Service Set Identifiers (SSID) and Twitter \#Brooklyn data - from selected neighborhoods of and about Brooklyn, New York. The aim is to show if and how these complex patterned linguistic practices - which so far have been neglected in corpus-assisted studies of urbanity and urban linguistics - carry the potential for (re-)indexing a number of values of an urban neighborhood and the Brooklynite community's identity. I will also show how it is possible to systematically compile these so far neglected types of data in urban spaces. Furthermore, to capture the complexities of discursive urban placemaking, multivariate data and quantitative and qualitative mixed methods will reveal how patterns of language usage, and their deviations, in various data types form the multiple and dynamic backgrounds for how foregrounded (Leech 1969, 2008) discursive urban place-making is created.

This study also builds on Busse and Warnke's (2015) urbanity model (Table 1). It is part of my own heiURBAN project whose ultimate goal is to analyze linguistic and other semiotic data from selected neighborhoods in Brooklyn, New York ranging from Brooklyn Heights, DUMBO, Park Slope, Bushwick, Greenpoint, or Red Hook. The aim is to unlock existent and evolving, at times contradictory, communicative practices in selected neighborhoods of Brooklyn, New York, as acts of discursive urban place-making.

Table 1: Model of urbanity (Busse and Warnke 2015).

\begin{tabular}{lll}
\hline Dimension: & Size & Density \\
\hline Action: & Heterogeneity & Simultaneity \\
Representation: & Multiformality & Multi-semiosis \\
\hline
\end{tabular}

The next section will outline the relevant literature, including the theoretical framework of the urbanity model (Busse and Warnke 2015), the process of discursive urban place-making and Leech's $(1969,2008)$ concept of foregrounding. 
It will analyze the photograph in Figure 1 to show the various modes and dimensions of the urbanity model and how places are made through semiotic signmaking. This is followed by a presentation of the linguistic and semiotic data included in the heiURBAN corpus - of which the photograph in Figure 1 is part and of the data analyzed in this study. Section 4 begins with a description of how the WiFi and the \#Brooklyn Twitter data were compiled into a structured query language (SQL) database. It then moves on to the analysis, findings, and interpretation of these data, which so far have not been considered in investigations of discursive urban place-making. The conclusions summarize major findings of this paper and connect these to a brief presentation of the so-called and soon to be launched heiURBAN platform.

\section{Literature review: discursive urban place- making, the urbanity model, and foregrounding}

\subsection{The model of urbanity}

A “spatial dimension” (Busse 2019: 20; Busse and Warnke 2015) may refer to the geographical coordinates of the physical environments. If human beings interact in a physical space, a space becomes a place endowed with meaning (Busse 2019; Cresswell 2015; Warnke 2017), which is constantly negotiated and contested. As the city, like any other space, is linguistically loaded, discourse in an urban space, that is, the use of linguistic and other semiotic modes in a context of urbanity, is one such social process of place-making. Urban spaces are parameters of linguistic variation, and language is "also a parameter for the construal of urbanity by means of place-making practices” (Busse 2019: 21; see also Warnke 2017).

In Busse and Warnke's (2015) model, the adjective urban describes a set of values of a place, neighborhood, or city. Conceptually, it denotes an evaluative rather than a descriptive relation. Hence, the terms urban/urbanity are prone to act as dynamic meaning-making concepts (see Busse and Warnke forthcoming) in complex and dense spatial constellation in a city. Following Lefebvre (1974), three modes - 1) dimension, 2) action and 3) representation - constitute the urbanity model (Busse and Warnke 2015) shown in Table 1.

If we transfer the conceptual configurations of the urbanity model to the photograph displayed in Figure 1, we see two discourse contexts of this photograph, one is who and what are in it and what they are doing; the other is that this is a picture made by a photographer who has intentionally included the photograph for his public exhibition. In the urbanity model, dimension describes spatial 
configurations. In the photograph, the dimensional configurations are materialized through Jerell Willis's body and the space in which the photograph with his son was taken, namely, on the Brooklyn Bridge, which connects the borough of Brooklyn with that of Manhattan.

For the second discourse context - that of the photographer choosing this photograph for his exhibition - the dimensional spatial configuration is that of depicting black fatherhood a) in New York and b) in a material exhibition. Action carries interpersonal dimensions and describes what agents do in space. In the photograph, Jerell Willis walks the Brooklyn Bridge carrying his son and displays his naked body, with the peculiar Brooklyn tattoo as semiotic place-making on the body. As a photographer, Zun Lee portrays an intimate moment between the father and his son. He also gives voice to a former Brooklynite of color. Representation describes the ways in which semiotic practices - linguistic or other - represent and construe meaning and places. In the photograph, this place-making is construed through multivariate sign-making - Brooklyn in the artistic font on the back of a human torso and by walking the bridge - and the specific and foregrounded design of the tattoo. Through the choice of the medium of a photograph on the discourse dimension of the photographer the meaning-making practice becomes not only permanent but also public.

In the urbanity model, the three modes are further characterized by six distinct features: size, density, heterogeneity, simultaneity, multiformality, and multisemiosis. Size and density further modify the dimensional mode because they allow for a more detailed description of the scope of an urban space under investigation. To refer this to the discourse contexts of the photograph, the features of size and density are metaphorically evoked through the Brooklyn Bridge - the cultural icon of the ethnically most diverse and densely populated megacity New York. Heterogeneity and simultaneity account for the fact that any action may be performed simultaneously and by various agents, as can be seen in the photograph for both discourse contexts. Despite the fact that the borough of Brooklyn is still part of Jerell Willis's identity, as a person of color he was pushed out of Brooklyn. Multiformality and multi-semiosis ensure that any semiotic practice or any incident are realized and construed by a multitude of forms which consist of different modes - tattoos, walking the bridge, the choice of creating a black-and-white photograph. The denser, more heterogeneous, and inter-semiotic a city is, the more urban it will be, and the more linguistic and semiotic variation will be encountered.

The photograph with Jerell Willis and his son Fidel illustrates, on various levels, the complexity of discursive urban place-making: fugitivity, because he was forced to leave his neighborhood, and futility, with the next generation on his arm, and, at the same time, maintaining black cultural belonging to a borough that no longer affirms black people's place in it, or at least not in those gentrified Brooklyn 
neighborhoods which are directly facing Manhattan. At the same time, it also negotiates precarious intimacy and relationships between him as the father and his son in a very public and even exhibited way. Added to this is that Brooklyn and the Brooklyn Bridge have various connotations for different people from different ethnic backgrounds.

Urban space is also characterized by the declarative function in Searle's (1976) speech act model. Linguistic and semiotic practices in urban spaces may be endowed with a declarative illocutionary force which has the potential for changing - in the sense of a declarative city - urban reality from space to place (Cresswell 2015) because they are embedded in the modes of dimension, action, and representation. These urban semiotic place-making practices and semiotic interventions may become indexical and have enregistering potential in the sense that a community of practice - temporarily or not - has endowed linguistic practices with certain social values (Agha 2003, 2005; see also Johnstone 2009, 2017; Monka et al. 2020). In other words, all linguistic and semiotic acts - not just dialect features alone (Johnstone 2009) - may be associated or linked with particular social values and may be used to do social work (Busse 2019). Jerell Willis's tattoo is a performative act in which Brooklyn is created as an artsy place and in which, through materially engraving art on his naked torso, the declaration also creates Brooklyn. The photographer's capturing of both his body and the moment of walking the bridge are equally declarative, as these processes lend this act permanence and publicity (see also Blommaert 2013; Britain 2018; Eckert 2012; Warnke 2017).

\subsection{Discursive urban place-making and foregrounding}

The question arises when we know that social value is meaningfully indexed with certain linguistic and semiotic patterns in various contexts of urbanity. For this, it is useful to unlock the interplay between quantification as seen in statistical foregroundedness, for example, as well as in the qualitative investigation of singular, multi-semiotic discursive practices existent in urban spaces. In his book Language in literature: Style and foregrounding, Geoffrey Leech regards the "varied applications of the concept of foregrounding" (2008: 4) as key to analyzing and explicating literary texts. On the basis of his definition of style as language variation according to varying circumstances, Leech (2008) illustrates the two dimensions of foregrounding, deviation and parallelism (Hakemulder 2020). For example, foregrounding may be "deviation, or departure, from what is expected in the linguistic code expressed through language [...]" and that "functionally, it is a special effect or significance conveyed by that departure" (Leech 2008: 3). In other words, conventions of language usage form the background for how linguistic structures become prominent. 
Hence, assessing foregrounding - through parallelism and deviation - is always also a comparative exercise. If style is variation in language usage, then each linguistic/semiotic choice is stylistic, multifunctional, and therefore socially meaningful in context and within (or devoid of) certain intra - and intertextual norms set up in space, time, or by certain communities of practice.

In order to further assess the extent of foregrounding mechanisms that can be discerned in the Jerell Willis example, I draw on my earlier work (Busse 2019). I was able to outline the tentative patterns of discursive urban place-making in a small corpus of 33,117 words consisting of semi-structured interviews and conducted in various gentrified neighborhoods of Brooklyn (such as Brooklyn Heights, Williamsburg, or Park Slope) in 2012. With the help of a keyword analysis, which assesses a text's aboutness through a statistical comparison of lexical items in the text under investigation with a reference corpus, I show that Brooklyn as a proper name is statistically marked in my interview data and I claim that it is used generically to enregister (Johnstone 2009) Brooklyn(C) as a brand. In the interview data, Brooklyn or the respective neighborhoods are constantly compared with Manhattan as a borough and the Brooklyn(c) values created are coolness, authenticity, a community - and neighborhood feeling, or striving for sustainability. Here is one example from a Brooklynite who answers the interview question "How would you describe this place?” by various generic references to Brooklyn as a brand:

(1) Like a lot of like it's very like homegrown, like grassroots, like a lot of people are like you know, if it's like you know oh this isn't made in Brooklyn or handmade in Brooklyn, it's like a cool [...] a little bit of an authentic city (interview with female Brooklynite, age group 30-40).

There are striking discursive similarities between the place-making practices/features identified in the interview corpus and in the photograph. The reference to Brooklyn on Jerell Willis's back also construes Brooklyn (C) as a brand, with the variation that it is on the body and multimodally and artistically crafted with the depiction of the iconic Brooklyn Bridge. However, the embodied art on Jerell Willis's back might also stand for a reclaiming of space following severe processes of gentrification already taking place in Brooklyn in 2012, when the photograph was taken. Brooklyn was then and still is also one of the most ethnically heterogenous neighborhoods of New York (Fessenden and Roberts 2011). While Brooklyn is described by some as an up-and-coming or "authentic" (Busse 2019) borough in which neighborhoods like DUMBO change their character from "artsy to digital DUMBO" and where many warehouses are turned into expensive condominiums, not much is said of a) those inhabitants who are pushed out of gentrified places or $b$ ) different ethnic communities to whom Brooklyn is home, too. Perhaps what we see here is a foregrounded (re-)claiming of place, even a resistance against the backdrop of "urban" place-making - which has so far been 
either romanticized or neglected and led to massive changes in Brooklyn - some call it gentrification and renewal, others call it dispossession and displacement.

Foregrounding through parallelism is therefore construed by the generic multimodal reference to the pattern of Brooklyn as a name on all dimensions of the urbanity model. This comparative exercise is crucial to capture how the semiotic place-making on the body of Jerell Willis's back relates to other, semiotically and diachronically distinct discursive urban place-making practices collected before and after the photograph was taken. The comparative exercise is also crucial to Busse and Warnke's (2015) urbanity model, both methodologically and theoretically. For the former, it highlights the mixed method approach - uniquely combining disciplines such as corpus linguistics, sociolinguistics, ethnography, urban geography etc. - and the claim to include in investigations of urban discursive place-making, for example, both quantitative and qualitative data and a diachronic perspective. For the latter, that is, theoretically, I rely on the Leechean notion that patterns of foregrounding can only be discerned through comparison of various linguistic practices in context.

Following the outline of the theoretical model of urbanity and its operationalization through the analysis of the photograph in Figure 1, the next session will introduce the heiURBAN corpus and data investigated further for this study.

\section{Data and methodology}

The data which constitute the heiURBAN corpus are multivariate, diachronic, multimodal, and multi-semiotic. The corpus has grown since the beginning of the project in 2012. Here is the timeline (Figure 2):

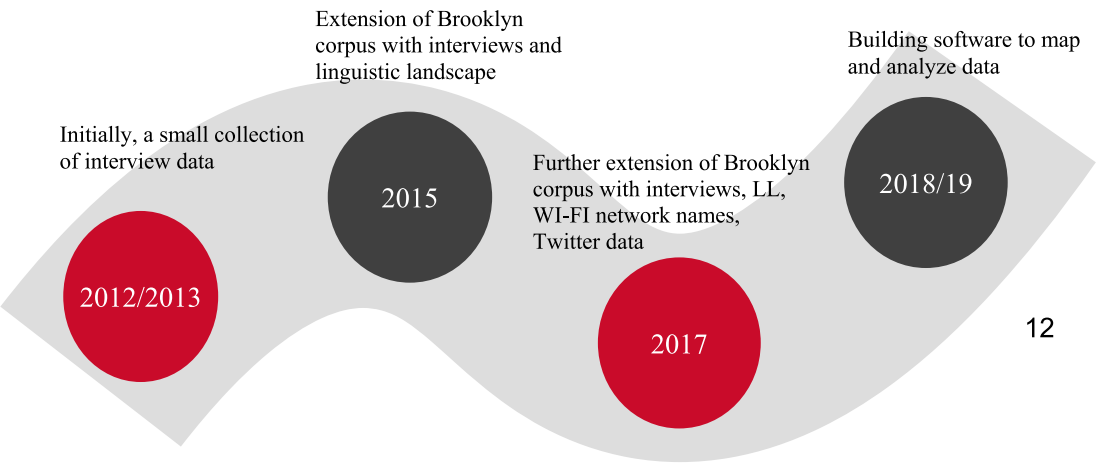

Figure 2: Timeline of data compilation for the heiURBAN corpus. 
In its current pre-Covid-19 status, the heiURBAN corpus looks as follows Table 2. For some types of data, the compilation is still in process.

Table 2: Data types in the heiURBAN corpus.

\begin{tabular}{ll}
\hline Type of data & Number of tokens/occurrences \\
\hline Interviews & $\begin{array}{l}\text { Currently ca. } 1.3 \text { million words } \\
\text { Currently ca. 8,000 photographs }\end{array}$ \\
Wi-Fi SSIDs Currently ca. 47,000 Wi-Fi SSIDs \\
Tweets
\end{tabular}

As can be seen in Figure 3, the interview data, the linguistic landscape data, and the Wi-Fi SSIDs were compiled in neighborhoods such as Brooklyn Heights, DUMBO, Park Slope, Williamsburg, Bedford-Stuyvesant, Greenpoint, Bushwick, and Red Hook in 2015 and 2017. These neighborhoods have already been gentrified or are in the process of becoming so. It could be said that they are - despite the separation through the East River - "facing Manhattan" and therefore have a certain (neoliberal) value.

All of these data are georeferenced. There are also field notes to the compilation processes.

For this paper, I draw on corpus linguistic and sociolinguistic methodology and extend the analysis by illustrating how I collected both the virtual - and in parts hidden - Wi-Fi Service Set Identifiers (SSID) and the Twitter data and how these function as foregrounded linguistic structures and patterns of place-making. The SSID names are selected and will be qualitatively analyzed. The Twitter data will be analyzed with the help of a sample of 50,000 Tweets and network theory. The following section will begin each with a detailed description of how the two data types - (i) the Wi-Fi SSIDs and (ii) the \#Brooklyn Tweets - were compiled and stored into the database. The description of the process of data compilation is then followed by a presentation of initial analytical findings. 


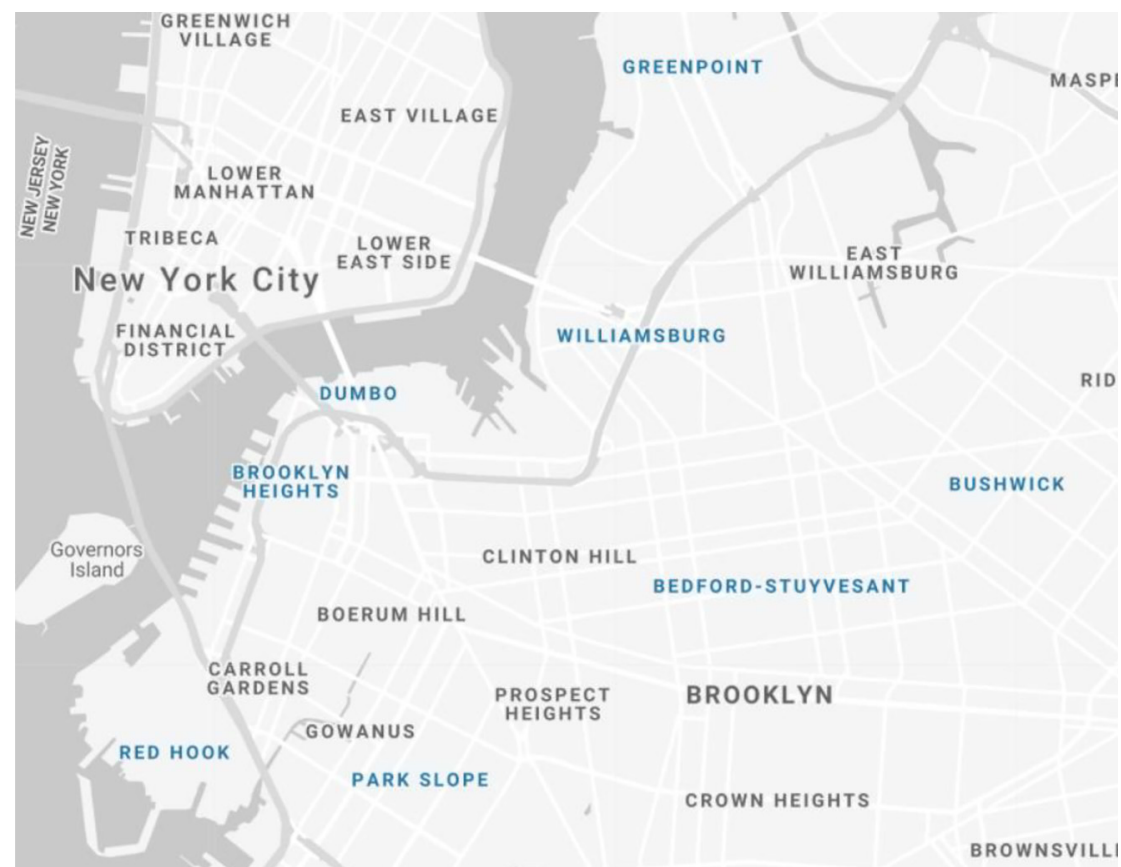

Figure 3: Map of Brooklyn and neighborhoods under investigation.

\section{Discursive urban place-making in Wi-Fi service set data and \#Brooklyn Tweets: data compilation, data analysis and initial findings}

\subsection{Wi-Fi SSIDs in Brooklyn, New York}

In this section, I will present both the methodology for collecting Wi-Fi Service Set Identifiers (SSIDs) for the heiURBAN corpus and show how that compilation process has been further developed. I will then present some of the first research findings of the analytical procedures which evolved around a) ways of identifying linguistic structures, b) categorizing meaningful Wi-Fi SSIDs and c) describing their functions as acts of discursive urban-place-making. Suggestions for categorizations of Wi-Fi SSIDs are based on the pioneering work Ingo Warnke and I did in Berlin in 2012 (see Busse and Warnke 2016). 
Wi-Fi SSIDs are the names people give to their wireless networks. With that, I do not mean the noisy data, primarily consisting of unchanged default network names, illustrated in Figure 4 and which I also found during our 2017-field trip.

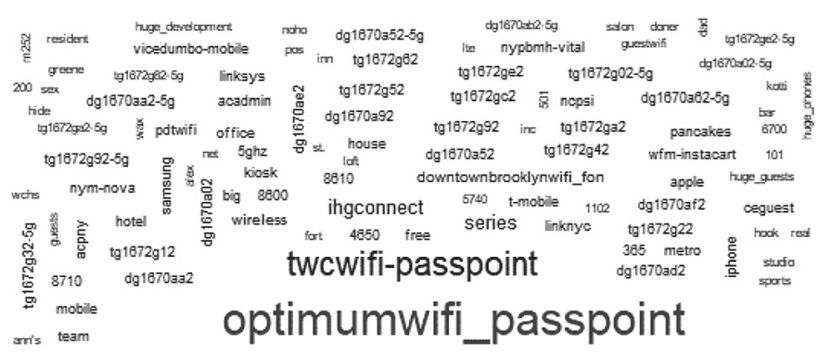

\section{optimumwifi}

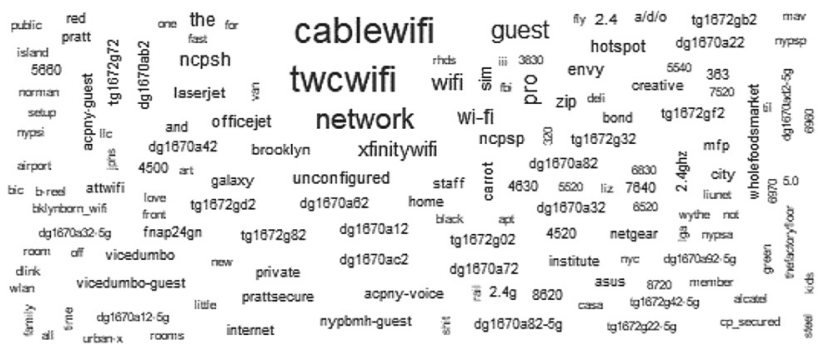

Figure 4: Noisy data in the Wi-Fi SSID collection process.

Contrary to these, I refer to the semantically meaningful labelling such as: "Don't throw food in our yard", found in Bedford Stuyvesant, "BackInBrooklyn", recorded in Williamsburg/Broadway Triangle, "Dumbo Time Capsule” recorded in Dumbo, or "Fuck Donald Trump”, recorded in Williamsburg.

Applying the urbanity model (Busse and Warnke 2015) to these examples, their dimension is the location in which these Wi-Fi SSIDs were found. Instead of just recording the neighborhood and their coordinates, my team and I recorded geocoordinates each time a network was encountered. As regards the dimension of mode, it is obvious that human beings have decided to exploit that semiotic potential given in Wi-Fi SSIDs and decided to label them. Their representation is primarily linguistic and human beings' linguistic creativity for naming is beyond limits and perhaps reinforced in an initially invisible sphere, as these can only be seen using a Wi-Fi-enabled device such as a smartphone (Stelthove 2019). They may also be changed continuously. Therefore, they are mutable and ephemeral. It 
is now possible to sample, compile, and code Wi-Fi SSIDs because wireless networks following the 802.11 standard (commonly known as Wi-Fi or WLAN) are identifiable by a user-defined name (IEEE 1999: 55). Interestingly, the standard does not specify the encoding of the SSID.

While this type of linguistic data is extremely interesting for research in urban linguistics, collecting the data is first of all a momentous and certainly not a trivial task. The methods of collecting and compiling Wi-Fi SSID data were both used and refined following a field trip to Brooklyn in 2017. Conducting a pilot study, my team and I used our smartphones to document SSIDs in certain areas by manually copying them out of the network connection manager. Geographical coordinates were then, whenever possible, automatically approximated.

My team and I then devised a new approach. In the field of information security, wardriving is a common practice involving the "the act of moving around a specific area, mapping the population of wireless access points for statistical purposes" (Hurley et al. 2007: 3) in order to identify vulnerable or weak networks. It has been repurposed for other types of research: semantic information for marketing purposes (Seneviratne et al. 2015), to investigate Wi-Fi use in public settings such as parks (Forlano 2008), as well as for ethnographic studies on social relationships (Hampton and Gupta 2008). However, this technique has seldomly been fused into a corpus or used by (socio)linguists to tap into hidden language data and urban place.

Therefore, for our 2017-field trip, my team and I automatized the SSID collection process by using WiGLE Wi-Fi Wardriving (Carra et al. 2020), an opensource mobile application for scanning and mapping wireless networks. In order to make the collection process as seamless as possible, all researchers carried a smartphone or tablet running the application which was constantly gathering all available access points including metadata such as the current location and the current signal strength. Therefore, the researchers were able to record all this data while walking the streets, interviewing people, and taking photographs of the linguistic landscape in those assigned streets representative of the specific neighborhood. While this approach worked very well, the researchers still needed to remember to keep their devices close to buildings due to the limited signal coverage of only 25-100 m (Cooklev 2004; Harwood 2011). At the end of each day, the data from all devices was transferred to an external storage device. Following the fieldwork, the individual datasets (multiple files per day per researcher) were combined, post-processed, and ultimately added to a SQL database. Since SSIDs are not unique, the unique Basic Service Set Identifier of the access points to disambiguate networks was used. Given that there are enough data points on one particular network, in many cases my team and I were also able to triangulate the 
position of the access point based on signal strength, giving us more detailed information about the origin of the message.

While many of the fundamental technical challenges can be solved this way, there are still a number of open questions. Firstly, there is no interaction with the creators of the SSIDs, and no socio-demographic information beyond an approximate location can be obtained. Secondly, SSIDs can be extremely ephemeral. Therefore, every SSID dataset has to be treated as a very specific kind of sample, which is highly dependent on the timing and the movement of the researchers. Lastly, one could debate the (non-)public nature of these names from a privacy perspective and whether it is ethically responsible to capture, locate, and analyze them.

\subsubsection{Categories and functions Wi-Fi SSIDs: first tentative results}

In our 2017-field trip my team and I collected about 47,000 Wi-Fi SSIDs in Bushwick, DUMBO, Greenpoint, Red Hook, Red Hook Projects, and Williamsburg. Our research questions included the following aspects:

- Which semiotic material do human beings in Brooklyn use for their Wi-Fi SSIDs?

- What is the linguistic structure of Wi-Fi SSIDs?

- What is the function of a labelled Wi-Fi SSID?

- Is it possible to categorize the Wi-Fi SSIDs according to these forms and function? And how does the interplay between form and function create an act of urban discursive place-making which is dependent upon and constructive of the neighborhood, street, and specific location in which they were geo-referenced?

- Do certain patterns emerge, and do they interact and correlate with or contradict practices of urban semiotic place-making in other types of data?

This section outlines both ways of how Wi-Fi SSIDs can be systematically compiled, assessed, and categorized. ${ }^{2}$ The degree and extent of foregroundedness can only be measured and unlocked within these multi-semiotic digital, physical, and material contexts. In the few studies on Wi-Fi SSIDs (Ferreira et al. 2013; Kindberg and Jones 2007; Könings et al. 2013; Seneviratne et al. 2015), their semantics and functions are often at the centre of analysis. Other studies (e.g. Stelthove 2019) suggest ways of categorizing them according to functionalsemantic criteria.

2 A detailed analysis of how the different forms and categories can be georeferenced both qualitatively and quantitatively to the different neighborhoods and then correlated to multi-semiotic practices of urban discursive place-making is the focus of a study currently in preparation. 
Table 3, which draws on Warnke and Busse (2015) and Stelthove (2019), will give a first glimpse into how the automatically collected 47,000 examples of Wi-Fi SSIDs were sampled in Brooklyn neighborhoods. The ultimate aim is to produce a relational database. The categories suggested have not been finalized yet. They are based on a sample investigation of $100 \mathrm{Wi}$-Fi SSID. The labels for each category can be more than one or they can also be ambiguous (Table 3).

Table 3: Criteria for categorizing Wi-Fi SSID.

\begin{tabular}{|c|c|}
\hline Category & Explanation \\
\hline Wi-Fi SSID & Lists the name of the Wi-Fi SSID. \\
\hline Geo-coordinates & Geo-reference of the coordinates of the Wi-Fi SSID. \\
\hline Neighborhood & $\begin{array}{l}\text { Names the neighborhood in which the Wi-Fi SSID was } \\
\text { found. }\end{array}$ \\
\hline Language used & $\begin{array}{l}\text { Informs about the language(s) used in the realization of the } \\
\text { Wi-Fi SSID name. }\end{array}$ \\
\hline Lexico-grammatical features & $\begin{array}{l}\text { Describes the linguistic structure of the Wi-Fi SSID in terms } \\
\text { of lexico-grammatical features. These may include the } \\
\text { coding of the name as a word, phrase, or a sentence or even } \\
\text { an acronym. It may also indicate an ambiguous status. }\end{array}$ \\
\hline Speech act & $\begin{array}{l}\text { Codes the type of speech act of the Wi-Fi SSID following } \\
\text { Searle (1976). }\end{array}$ \\
\hline $\begin{array}{l}\text { Onomasticon (referring to personal } \\
\text { names, toponyms) }\end{array}$ & $\begin{array}{l}\text { Onomasticon describes whether the Wi-Fi SSID is a per- } \\
\text { sonal name or a toponym. }\end{array}$ \\
\hline Type of place & $\begin{array}{l}\text { Concerns whether the Wi-Fi SSIDs referred to a house, a } \\
\text { street, a general location, an area or a neighborhood, } \\
\text { borough, city, a landscape, a country, a region, or continent } \\
\text { (Busse and Warnke } 2015,2016 \text { ). }\end{array}$ \\
\hline Themes and place-making discourse & $\begin{array}{l}\text { Codes the themes/topics to which the names refer. They } \\
\text { may cover the entire spectrum of human existence and } \\
\text { ontologies (that is ranging from music and pop to biology, } \\
\text { computational science, politics etc.). }\end{array}$ \\
\hline $\begin{array}{l}\text { Contextual with the city under } \\
\text { investigation }\end{array}$ & $\begin{array}{l}\text { Records if the term specifically refers to the city, neigh- } \\
\text { borhood, or borough under investigation. }\end{array}$ \\
\hline Enregisterment & $\begin{array}{l}\text { Referring to Johnstone (2009), I record if the Wi-Fi SSID } \\
\text { contains linguistic elements (e.g., dialect features) that } \\
\text { carry indexical value. }\end{array}$ \\
\hline
\end{tabular}

Let us look at a randomly selected list of examples from our corpus (Table 4) and see how these may be categorized: 


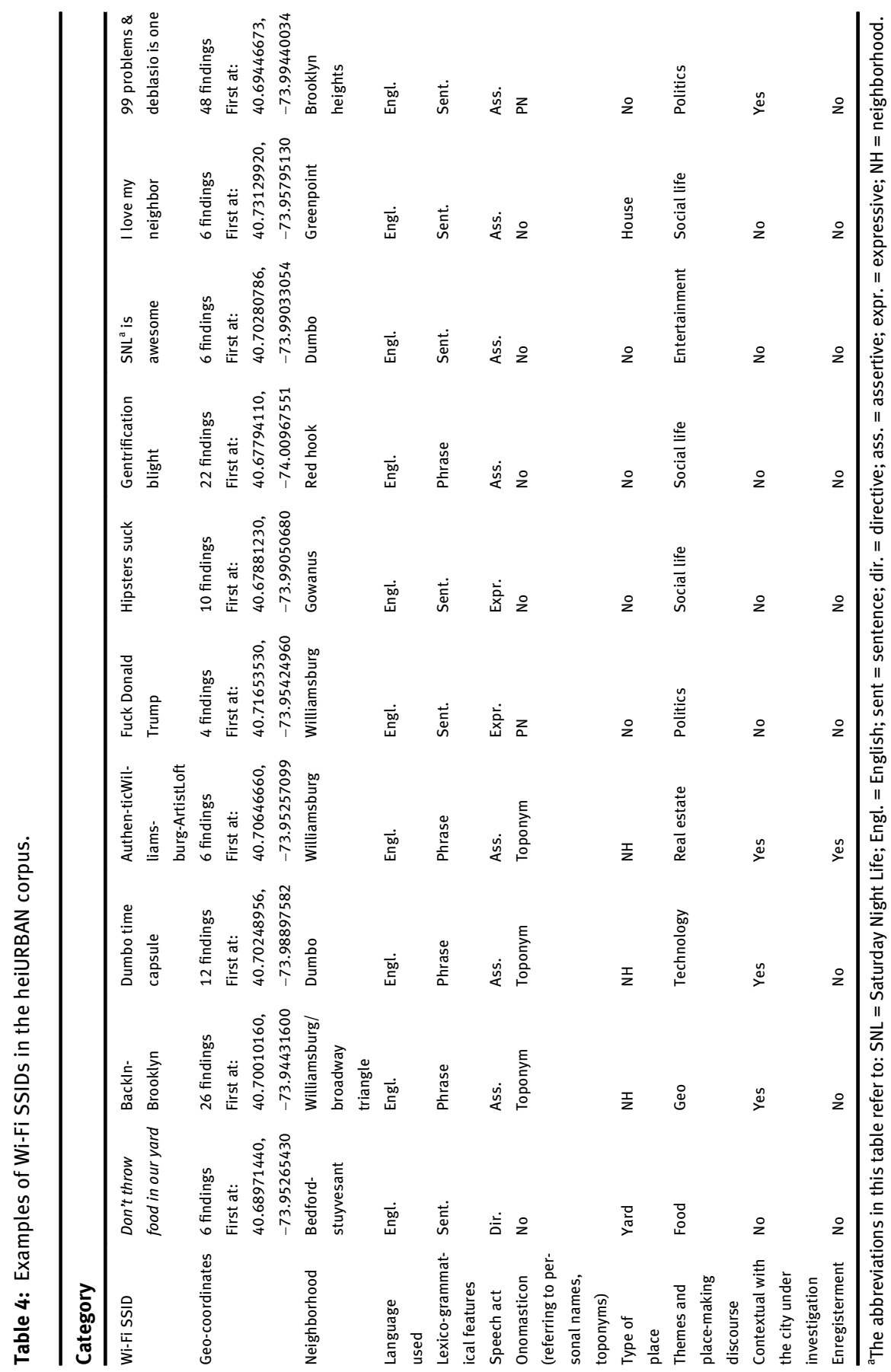


The linguistic realizations of these Wi-Fi SSIDs range from phrases ("TheRealBushwickCountryClub") to sentences ("I love my neighbor.”). Reference is made to personal names (Trump, Deblasio) or acronyms or initials (SNL). Mention is also made of the neighborhoods (Williamsburg, Dumbo) or Brooklyn as a borough. The number indicates how often this SSID was recorded during my field trips. While this could indicate that there are multiple networks with the same name, it is more likely that the same network was encountered more than once. This is a striking phenomenon, which needs to be followed up because the question remains: who will take up and replicate which Wi-Fi SSID?

Wi-Fi SSIDs' discursive function of creating a place also becomes obvious in these selected examples. Some express political opinions (Fuck Donald Trump, 99 Problems and Deblasio is one). Others are comments on the process of gentrification (Hipsters Suck, Gentrification Blight) or they describe one's property in terms of the neighborhood (AuthenticWilliamsburgArtistLoft). Wi-Fi SSIDs are also used to communicate with neighbors through various types of speech acts, such as impolite imperatives like "Don't throw food in our yard", statements like "I can hear you fucking” or "I love my neighbor". These are striking ways of communicating because they are not overtly signposted on immediately visible posters, signs, or murals. On the contrary, they are initially hidden.

Therefore, each of the examples is a unique mobile sign of human interaction and living culture in urban spaces functioning as discursive urban place-making in need of individual analytical attention as a semiotic artefact. At the same time, they are part of a more general practice of patterned discursive social and cultural positioning which, as a practice of "public privatism” (Abdel-Aziz et al. 2016: 489), is mobile, ephemeral, and only digitally visible if one shows the intention to disclose it.

\subsection{Networks of Tweets with \#Brooklyn node}

\subsubsection{Data compilation}

Tweets like those displayed in (2) and (3) below represent complex multimodal ways of creating urban places, because \#-discourse establishes meaningful \#-connections between one or many hashtags and themes. In example (2), the Brooklyn neighborhood Bushwick is positively identified with street art as "the best neighborhoods for \#streetart”. In the second example, Brooklyn as a borough in general and Bushwick as one neighborhood in particular are criticized as "unethical" in relation to the real estate business. 
(2) "I may very well live in one of the best neighborhoods for \#streetart $\bullet$ So lucky. \#bushwick” (Fordyce 2017).

(3) "So unethical \#bushwick \#brooklyn \#realestate \#residentialrealestate

https://t.co/gJZxx0lyBY” (@100Bogart).

We have already encountered both of these contradictory patterns of urban discursive place-making: a) praise of Brooklyn (neighborhoods) for their artsy scene and $b$ ) severe criticism of gentrification processes.

Referring these practices to the urbanity model, we can assess that the dimensional mode is realized by when and from where the Tweet was posted. Action and representation strongly interact despite the restrictions on the number of signs used for Tweets. Unlike with Wi-Fi SSIDs, where the sender cannot usually be identified, the actional mode can be related to the persona posting the tweet. Similar to the WiFi SSIDs, the representation of Tweets can be realized multimodally and in complex meaning-making networks through re-posting, liking, re-tweeting, hashtagging and (re-)connecting. It is due to this complex weaving of Tweets that the features of the modes of the urbanity received additional complexity.

For the purpose of this paper, I shall analyze the individual \#Brooklyn Tweets and interpret their function or contextualize them. On the basis of big data analysis, the aim is rather to try to assess quantitatively the rhizome-like semantic \#Brooklyn- interconnection to find out if and how these form digital patterns of discursive urban place-making. The method used is network analysis.

Over the course of over three years, starting in January 2017, I have compiled and stored Brooklyn and Brooklyn-related Tweets and hashtags in order to investigate how these are tagged further and related to other topic markers (Zappavigna 2015). Currently, there are approximately 120 million Tweets and metadata. Although, this is still in the realm of small Big Data, it is a challenge to analyze or even view the data with traditional (corpus linguistic) software because of the dynamic nature and the highly intricate metadata situation. Another challenge lies in cleaning the data by filtering out duplicates, unrelated, and nonsensical Tweets from the dataset.

The sampling process, which led to the samples underlying the visualizations in Figures 5 and 6, is relatively complex, too, and possibly introduces certain biases. Generally speaking, I consider the population to be all Tweets in some way referring to Brooklyn that are being tweeted. For this particular project, my team and I defined the population more restrictively to be all Tweets referring to a) Brooklyn and b) being posted in 2019. Due to the fact that it is impossible to collect all Tweets being tweeted, the heiURBAN Twitter corpus is already only a small sample of the population. 


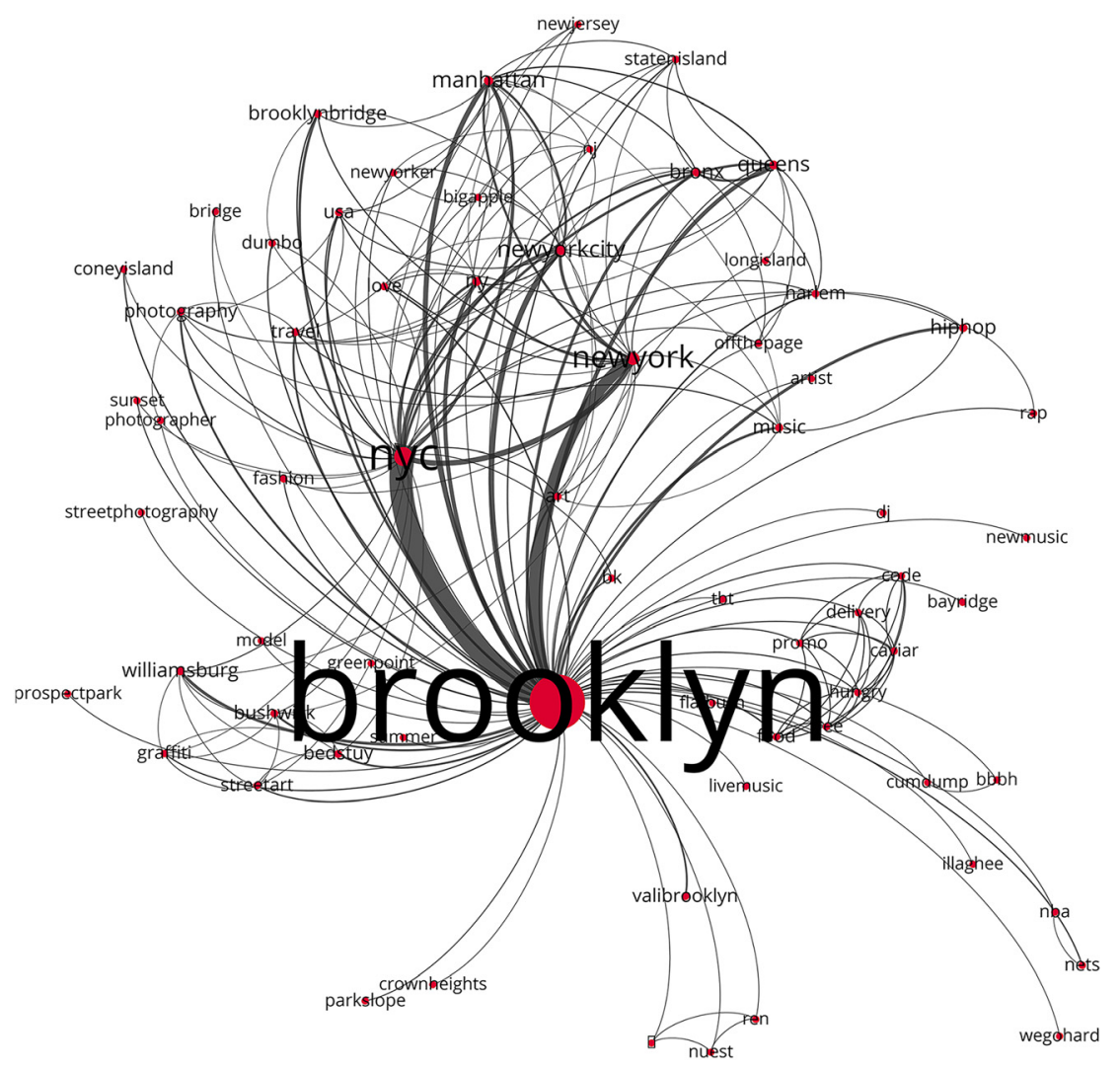

Figure 5: Co-occurrence network (50,000 Tweets from 2019, all containing the hashtag \#Brooklyn).

In order to compile the heiURBAN Twitter corpus, public Tweets, based on a predefined set of search terms and hashtags as well as on geolocation, ${ }^{3}$ have been continuously collected using Twitter's standards streaming/filtering Aplication

3 The following list of search terms has been extended with neighborhood hashtags as well as hashtags for New York City in mid-2017. In January 2018, location-based archival was added.

Search terms and hashtags: \#brooklyn, \#dumbo, \#brooklynsmainstreet, \#brooklynbridge, \#onlyinbrooklyn, \#Ltrain, \#Brooklyn, \#brooklyn, \#williamsburg, \#bushwick, \#nyc, \#newyork, \#carrollgardens, \#prospectheights, \#parkslope, \#gowanus, \#redhook, \#bedstuy, \#crownheights, \#greenpoint, \#bedfordave

Geo bounding box: [-74.05663, 40.551042, -73.833365, 40.739446]. 


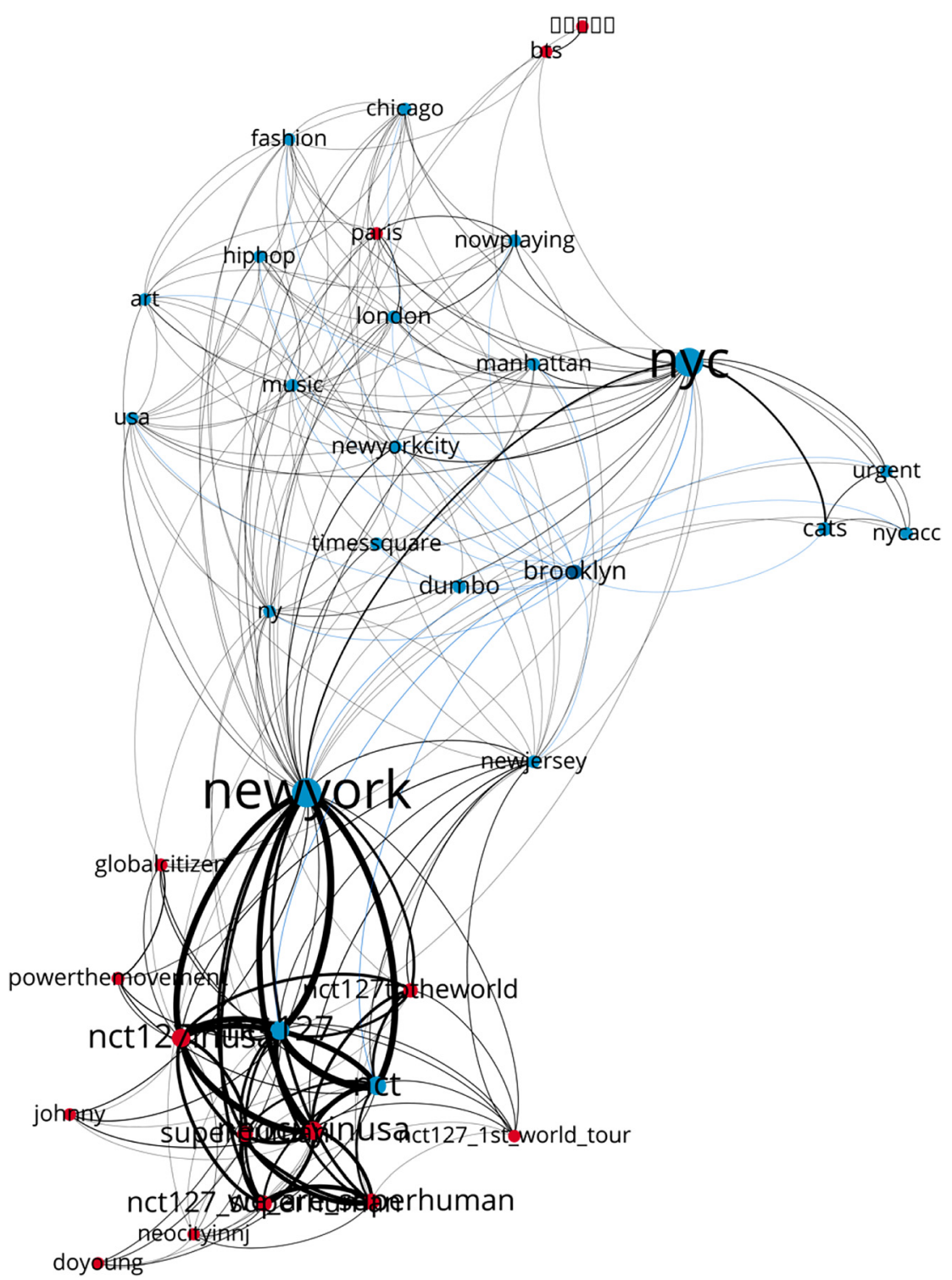

Figure 6: Co-occurrence network (100,000 randomly sampled Tweets from 2019; \#Brooklyn and directly connected nodes are blue). 
Programming Interface (API) ${ }^{4}$ (using TweetPinna to access the API and store the Tweets continuously). It is important to note that this API (in contrast to the commercial PowerTrack API with access to the full Twitter firehose) has various limitations and has been changed multiple times since 2017.

Unfortunately, collecting Tweets this way does not ensure that all collected Tweets are actually from the population. Also, the smaller the set of search terms and the more restrictive the filters are, the higher the chances of missing Tweets belonging to the population. Therefore, in order to capture more Tweets and to increase our chances of actually sampling the population, hashtags and search terms referring to New York City (and NYC) were added. While this approach adds a large amount of noise to the dataset, it allows us to carefully filter Tweets after the collection process at our own pace although Zappavigna (2018) points out that sampling based on hashtags always is impacted by the self-selecting nature of users using hashtags. Unfortunately, due to changes in Twitter's API as well as server maintenance, there are some days during which no data has been collected.

For 2019, the period in question, the database contains 339,437,44 Tweets. However, as indicated above, given the wide search parameters, many of these sampled Tweets are not part of the above-mentioned population. Usually, it is now necessary to apply sophisticated filter and categorization approaches in order to select those Tweets, which fit the population definition. For the visualizations above, we created one filtered and one unfiltered sample to demonstrate this. However, since links to \#Brooklyn are in focus, non-related Tweets will not impact the relationships in question, but only frequencies.

Out of these 339,437,44 Tweets, Figures 5 and 6 show two random samples. The sample for Figure 5 contains 50,000 Tweets, each of them containing the hashtag-type \#brooklyn (case-insensitive and sensitive to this spelling, so not “\#Bklyn" or "\#Bkln”.). While this choice skews the frequency of the \#brooklyn hashtag and limits the sample heavily, it will definitely ensure that the sample only contains Tweets from the actual population (Figure 5). The second, larger sample (Figure 6) contains 100,000 Tweets and has no restriction on content. Thus, this second sample is more representative of the whole corpus but will most likely include Tweets which are not part of the population as well as Tweets without any hashtags.

The visualizations show hashtag co-occurrence graphs (networks). The graphs have been constructed by looking at which hashtags are co-occurring in the sampled Tweets. Technically, this has been achieved by using a custom-built Python tool based on NetworkX (Hagberg et al. 2020). In the graphs, each node

4 See https://developer.twitter.com/en/docs/tweets/filter-realtime/api-reference/post-statusesfilter. 
represents one hashtag (all hashtags are lowercased), and edges represent if and how often hashtags co-occur within Tweets. The size of the nodes is a scaled representation of the hashtag frequency in the sample. Similarly, the width of the edges is a scaled representation of the frequency of co-occurrence.

\subsubsection{First tentative results in networks with node \#Brooklyn}

Figures 5 and 6 illustrate some revealing results. As was already the case in the photograph by Zun Lee (2012) and is also outlined in Busse (2019), Brooklyn as a neighborhood is frequently generically referred to by the hashtag \#Brooklyn (Figure 5). There is a measurable foregrounded connection between \#Brooklyn and \#NYC and \#newyork (Figure 6), which is construed through repetition of the relationship as parallel structure between these hashtag-items. Although this correlation might have been expected as Brooklyn is a borough of the City of New York, the reference to \#Brooklyn is much more prominent than that made to \#NYC or \#newyork. Also, the extent of the scaled edges, size, and widths foreground this relationship, especially in comparison to the other edges as well as their lengths and widths.

There is an interesting connection between \#Brooklyn and some of its gentrified neighborhoods (Figure 5): Williamsburg, Bushwick, and Park Slope. This illustrates that reference to these neighborhoods is made by the generic reference to that neighborhood. Also, the declarative styling of typical artsy features (Figure 6) that are connected to these neighborhoods are also - perhaps romantically - construed through particular co-occurring hashtags like \#graffiti and \#streetart, which add semantic and evaluative content to the hashtags used (Zappavigna 2018).

In summary, both Wi-Fi SSIDs and \#Brooklyn Tweets function as intricate practices of urban discursive place-making. Their systematic compilation as both a big and small process is complex and in need of digital tools and procedures which goes beyond that provided by corpus linguistics.

\section{Conclusion}

This paper has illustrated complex practices of urban discursive place-making in selected neighborhoods of Brooklyn, New York. These function as multimodal and multidimensional discourses, constructions, and reflections of an urban place.

Drawing on Busse and Warnke's (2015) urbanity model and using complex and hitherto neglected embodied and digital data (Wi-Fi SSIDs and Tweets), I have shown their compilation processes and outlined methodological procedures for how 
to systematically analyze these. Embodied semiotic landscaping, on the one hand, and digital semiotic data, on the other, function as highly creative individual, societal, public, and private semiotic markers of human existence, everyday life, culture, politics, and even protest. Although it remains to be studied how these practices are appropriated by other users. Also, how an observer, a citizen and a Brooklynite in a particular neighborhood identifies with it or remains distant must be further studied. And yet, it is the urban linguist's task to unlock these processes and transfer their meanings to the public. These practices of urban place-making are crucial processes and examples of how we live, interact, and position ourselves in this material - hopefully soon, post-Covid-19 - world. For Brooklyn, this has a global dimension as well (see Busse 2018), which needs to be systematically studied.

Therefore, the heiURBAN platform displayed in Figure 7 visualizes this positioning and aims at new ways of mapping multimodal linguistic and semiotic data and exploring them in 3D-mode. In Figure 7, it becomes obvious that all of these data points marked by the specific icons - for the Wi-Fi SSIDs or for the Twitter data - are clickable so that the content of the respective data points can be looked at individually and in context. Also, the goal of displaying the urban space data in 3D-mode is to ultimately raise the level of abstractions in order to highlight foregrounded patterns or deviations from them in respective streets or neighborhoods.

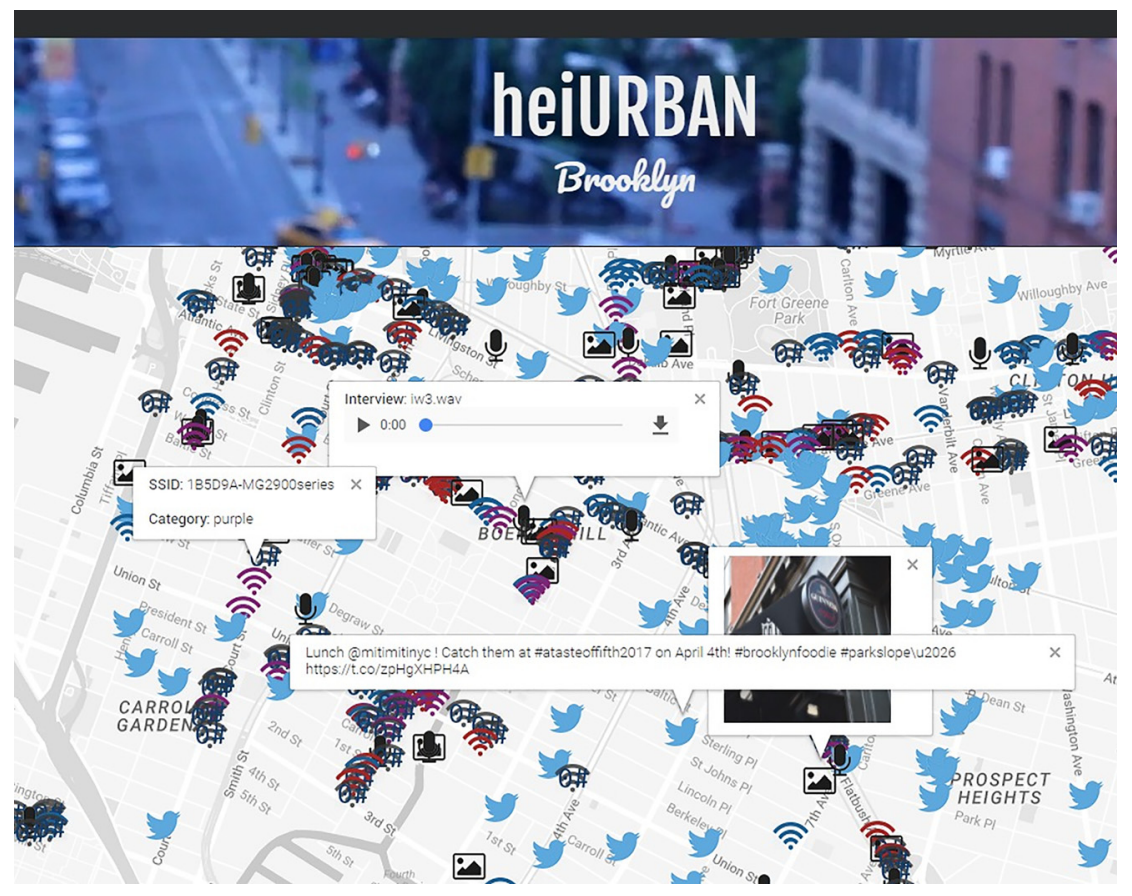

Figure 7: Screenshot of the heiURBAN corpus platform. 
Ultimately, this platform contributes to urban linguistics and is a scientific construction of place, despite its reduction of a lab-like arrangement of elements, which however tries to account for the complex and densely interwoven discursive practices in urban space - relevant also to urban planners, politicians, or architects.

In the future, the platform will visualize and provide an analytical tool to investigate how urban environments are socially and culturally superdiverse and therefore highly dynamic in nature, not only because linguistic and semiotic data densely condensate in this particular constellation of space. Any type of data is meaning-making and discursive and the discourse which is construed and reflected in an urban space is data to be analyzed, despite the complexity of the endeavor.

Acknowledgments: I would like to thank Ingo Kleiber for his outstanding work on producing the networks in this paper.

\section{References}

Abdel-Aziz, Ayat Ayman, Hassan Abdel-Salam \& Zeyad El-Sayad. 2016. The role of ICTs in creating the new social public place of the digital era. Alexandria Engineering Journal 55(1). 487-493.

Agha, Asif. 2003. The social life of cultural value. Language \& Communication 23(3-4). 231-273. Agha, Asif. 2005. Voice, footing, enregisterment. Journal of Linguistic Anthropology 15(1). 38-59. Blommaert, Jan. 2013. Ethnography, superdiversity and linguistic landscapes: Chronicles of complexity. Bristol: Channel View Publications.

Britain, David. 2018. Beyond the 'gentry aesthetic': Elites, received pronunciation and the dialectological gaze in England. In Crispin Thurlow \& Jaworski Adam (eds.), Elite discourse: The rhetorics of status, privilege and power, 46-56. London: Routledge.

Busse, Beatrix. 2018. Current British English: Sociolinguistic perspective. In Vaclav Brezina, Katrin Aijmer \& Robbie Love (eds.), Corpus approaches to contemporary British speech: Sociolinguistic studies of the spoken BNC2014, 16-26. London: Routledge.

Busse, Beatrix. 2019. Patterns of discursive urban place-making in Brooklyn, New York. In Viola Wiegand \& Michaela Mahlberg (eds.), Corpus linguistics, context and culture, 13-42. Berlin: Mouton de Gruyter.

Busse, Beatrix \& Ingo H. Warnke. 2015. Sprache im urbanen Raum - Konzeption und Forschungsfelder der Urban Linguistics. In Ekkehard Felder \& Andreas Gardt (eds.), Handbuch Sprache und Wissen, 519-538. Berlin: Mouton de Gruyter.

Busse, Beatrix \& Ingo H. Warnke. 2016. Virtual variation as part of virtual recognition: On the economy of naming practices in Wi-Fi network names. Berlin: The Sociolinguistic Economy of Berlin. https://www.geisteswissenschaften.fu-berlin.de/en/v/socling-berlin2016/ abstracts/Virtual-variation-as-part-of-virtual-recognition-_-On-the-economy-of-namingpractices-in-Wi-Fi-network-names.html (accessed 16 April 2021).

Busse, Beatrix \& Ingo H. Warnke. forthcoming. Introduction. In Beatrix Busse \& Ingo H. Warnke (eds.), Language in urban space, 1-88. Berlin: Mouton de Gruyter, In preparation.

Carra, Andrew, Robert Hagemann \& Hugh Kennedy. 2020. WiGLE Wi-Fi wardriving. https://github. com/wiglenet/wigle-Wi-Fi-wardriving (accessed 16 April 2021). 
Cooklev, Todor. 2004. Wireless communication standards. A study of IEEE 802.11, 802.15, and 802.16. New York: Standards Information Network.

Cresswell, Tim. 2015. Place: An introduction, 2nd edn. Malden: Wiley Blackwell.

Eckert, Penelope. 2012. Three waves of variation study: The emergence of meaning in the study of variation. Annual Review of Anthropology 41. 87-100.

Ferreira, Ana, Jean-Louis Huynen, Vincent Koenig, Gabriele Lenzini \& Salvador Rivas. 2013. Sociotechnical study on the effect of trust and context when choosing Wi-Fi names. In Rafael Accorsi \& Silvio Ranise (eds.), Security and trust management. STM 2013. Lecture notes in computer science, vol. 8203, 131-143. Berlin \& Heidelberg: Springer.

Fessenden, Ford \& Sam Roberts. 2011. Then as now - New York's shifting ethnic mosaic. The New Yorker. http://archive.nytimes.com/www.nytimes.com/interactive/2011/01/23/nyregion/ 20110123-nyc-ethnic-neighborhoods-map.html?_r=0 (accessed 16 April 2021).

Fordyce, Bec. 2017. @becfordyce. Twitter post. 06:56 p.m. https://twitter.com/becfordyce/ status/819603919508742145 (accessed 16 April 2021).

Forlano, Laura. 2008. Anytime? Anywhere? Reframing debates around municipal wireless networking. The Journal of Community Informatics 4(1). https://doi.org/10.15353/joci.v4i1.2967.

Hagberg, Aric A., Daniel A. Schult \& Pieter J. Schwart. 2020. NetworkX reference. https://networkx. github.io/documentation/latest/_downloads/networkx_reference.pdf (accessed 16 April 2021).

Hakemulder, Frank. 2020. Finding meaning through literature. Anglistik 31(1). 91-110.

Hampton, Keith \& Neeti Gupta. 2008. Community and social interaction in the wireless city: Wi-Fi use in public and semi-public spaces. New Media \& Society 10(6). 831-50.

Harwood, Mike. 2011. CompTIA network+ (N10-004) cert guide, 1st edn. Indianapolis, IN: Pearson Education Inc.

Hurley, Chris, Thornton Frank, Russ Rogers, Connelly Dan \& Brian Baker. 2007. WarDriving \& wireless penetration testing. Rockland, MA: Syngress Pub. http://search.ebscohost.com/login.aspx? direct=true \&scope $=$ site $\& d b=$ nlebk $\& d b=$ nlabk $\& A N=176007$ (accessed 16 April 2021).

IEEE. 1999. 802.11a-1999 - IEEE standard for telecommunications and information exchange between systems - LAN/MAN specific requirements: Part 11: Wireless medium access control (MAC) and physical layer (PHY) specifications: High speed physical layer in the $5 \mathrm{GHz}$ band. New York: Institute of Electrical and Electronics Engineers. http://ieeexplore.ieee.org/ servlet/opac?punumber=6606 (accessed 16 April 2021).

Johnstone, Barbara. 2009. Pittsburghese shirts: Commodification and the enregisterment of an urban dialect. American Speech 84(2). 157-175.

Johnstone, Barbara. 2017. Characterological figures and expressive style in the enregisterment of linguistic variety. In Chris Montgomery \& Emma Moore (eds.), Language and a sense of place: Studies in language and region, 283-300. Cambridge: Cambridge University Press.

Kindberg, Tim \& Timothy Jones. 2007. 'Merolyn the phone': A study of bluetooth naming practices. In John Krumm, Gregory D. Abowd, Aruna Seneviratne \& Thomas Strang (eds.), UbiComp 2007: Ubiquitous computing. Lecture notes in computer science, vol. 4717, 318-335. Berlin \& Heidelberg: Springer.

Könings, Bastian, Christoph Bachmaier, Florian Schaub \& Michael Weber. 2013. Device names in the wild: Investigating privacy risks of zero configuration networking. IEEE Mobile Data Management 2. 51-56.

Lee, Zun. 2012. Jerell Willis carries his son Fidel across the Brooklyn Bridge. PhotoJournal. http:// www.zphotojournal.com/zun-lee (accessed 16 April 2021).

Leech, Geoffrey. 1969. A linguistic guide to English poetry. London \& New York: Longman. Leech, Geoffrey. 2008. Language in literature: Style in foregrounding. Harlow: Longman. 
Lefebvre, Henri. 1974. La production de l'espace. Paris: Anthropos.

Monka, Malene, Pia Quist \& Astrid Avnskovse. 2020. Place attachment and linguistic variation: A quantitative analysis of language and local attachment in a rural village and an urban social housing area. Language in Society 49(2). 173-205.

Searle, John. 1976. A classification of illocutionary acts. Language in Society 5. 1-23.

Seneviratne, Suranga, Fangzhou Jiang, Mathieu Cunche \& Aruna Seneviratne. 2015. SSIDs in the wild: Extracting semantic information from Wi-Fi SSIDs. In The 40th IEEE conference on local computer networks (LCN), Oct 2015, 1-5. Clearwater Beach, Florida, United States. hal01181254. https://hal.inria.fr/hal-01181254.

Stelthove, Helen. 2019. Pretty fly for a Wi-Fi: A-Z Das Unvollständige Wörterbuch Der WLAN-Namen in Deutschland. Berlin: Duden.

Warnke, Ingo H. 2017. Raum, Ort, Arena und Territorium - vier Ebenen der Analyse verorteter Schrift. In Jin Zhao \& Michael Szurawitzki (eds.), Nachhaltigkeit und Germanistik. Fokus, Kontrast und Konzept, 135-158. Frankfurt: Lang.

Zappavigna, Michele. 2015. Searchable talk: The linguistic functions of hashtags. Social Semiotics 25(3). 1-18.

Zappavigna, Michele. 2018. Searchable talk: Hashtags and social media metadiscourse. London \& New York: Bloomsbury Academic.

\section{Bionote}

\section{Beatrix Busse}

Department of English, University of Cologne, Cologne, Germany

beatrix.busse@uni-koeln.de

https://orcid.org/0000-0003-4696-6727

Beatrix Busse received her PhD from the University of Münster and is currently Professor of English Linguistics and the Vice-Rector for Student Affairs and Teaching at the University of Cologne. Her research interests include stylistics, corpus linguistics, history of English and historical pragmatics, sociolinguistics, language in urban space with a focus on Brooklyn, New York, and transfer linguistics. Her most recent book-length publication is Speech, Writing and Thought Presentation in 19th-Century Narrative Fiction. A Corpus-Assisted Approach (2020, Oxford University Press). 